\title{
Development of teachers' reflective thinking, epistemological beliefs and attitude towards inclusion to support diversity in the classrooms
}

\author{
Preeti Verma $^{1}$, Deepshikha Mathur ${ }^{2}$ \\ ${ }^{1}$ Professor, Department of Special Education, SNDT University \\ ${ }^{2}$ Research Scholar, Department of Special Education, SNDT University, Mumbai \\ Corresponding author: Deepshikha Mathur \\ E-Mail: deepshikhamat@gmail.com
}

\begin{abstract}
Background: The purpose of this study is to describe and explain how the researchers developed and implemented an intervention module to affect reflective thinking, Epistemological Beliefs and Attitude towards inclusion in mainstream teachers to support diversity in a mainstream classroom.

Methodology: The experimental study was two group pre and post-test repeated measure design. Participants $(\mathrm{N}=94)$ were full-time mainstream school teachers with 54 in control group and 40 assigned to experimental group. The key concepts of reflective thinking, epistemological beliefs and attitude towards inclusion were operationalized through the development and implementation of an intervention module. Data was collected through pre and post questionnaire. To measure the effectiveness of the intervention, paired samples $t$-test was conducted to compare pre and post test scores.

Results: Results demonstrated a significant difference in the pre-test to post-test means of three variables in experimental group while control group showed no significant difference indicating a positive progression in teachers reflective thinking, epistemological beliefs and attitude towards inclusion.

Conclusion: Results of the study indicated introducing short direct intervention module to enhance reflective thinking, epistemological beliefs and attitude towards inclusion of mainstream teachers as integral part of teacher training programs. Teachers' attitudes towards inclusion can be changed cognitively but it takes time to change the affective and behavioral aspect. Teacher training programmes should first try to influence the epistemological beliefs and reflective thinking and then the attitude towards inclusion as feelings and beliefs have profound influence on how we receive and cognitively process the information.
\end{abstract}

Keywords: reflective thinking, epistemological beliefs, inclusion, attitudes towards inclusion

(Paper received $-10^{\text {th }}$ February 2020, Peer review completed $-20^{\text {th }}$ February 2020)

(Accepted $-24^{\text {th }}$ February 2020)

\section{INTRODUCTION}

Inclusion of children with disabilities creates new and unfamiliar situations in mainstream schools that need to be managed by the teacher. It requires new, innovative approach along with the technical understanding and skill to deal with these situations. A major part of responding to the diversity found inside the classroom is through effective and efficient teacher preparation [1-2]. Teacher's role in sustaining inclusive classrooms is undeniable and they require suitable supports and barrier free environment to sustain it [3]. Besides these external factors, there is a personal internal dimension for each teacher that supports inclusion. It is a deep understanding of knowledge, maturity in thinking and the attitude to accept inclusion.

Inclusion is defined as a process of increasing the participation of students in, and reducing their exclusion from, the cultures, curricula and communities of local centres of learning [4]. Teachers seem to endorse inclusive education in general, but do not like to be involved when it concerns their own teaching practice 
[5-6]. Teachers always express that it's difficult to include due to large number of reasons like paucity of time, lack of technical knowledge etc. Experts are not always present to give solutions or guide the teacher. Most of the time it's the teacher's personal attitude, beliefs and thinking that pushes the inclusion agenda in her class.

Attitude is everything and authors [7] have explained that attitudes are underlying dispositions which determine, along with other influences, a variety of behaviours towards an object. Attitudes toward disabilities reflect beliefs about people with disabilities and guides behaviour towards them [8]. When a group is established, stereotypical beliefs are attached to the group and people with disabilities fall into a group [9]. Wherever students have been successful, it has been usually because staff has been prepared to give the students' a fair chance, treating the person as an individual and not prejudging their abilities due to strong stereotypes attached to children with disabilities. Negative attitudes based on traditional thinking act as a big social barrier contributes to reduced self-efficacy leading to teacher stress [10]. Many factors influence attitudes: the degree and nature of children' disabilities, the teachers' experience with children with disabilities, the confidence in their own capabilities to implement inclusive activities, the curricula and so on. Teachers doubt their preparedness and competence to teach both regular learners and learners with special educational needs. It's the type of thinking, attitude and beliefs that influences a person's behaviour [11].

Teachers' attitudes towards inclusion present a confusing picture [12]. While some studies report negative attitudes towards inclusion of children with disabilities [13-14] others report a positive attitude [15-17]. If educators hold positive attitudes towards inclusive education it may encourage practices that will further successful inclusion of all students [18-19].

Teachers' beliefs about disability may be part of a broader set of beliefs called epistemological beliefs. Epistemological beliefs (EB) are ideas of individuals about what knowledge is and how knowledge and learning come to exist [20]. Having high epistemological belief is also necessary for inclusion. Epistemology essentially studies the nature, source and components of knowledge and even if the existence of that knowledge is possible [21]. Belief is different from attitude. Belief is the acceptance of a statement of a set of circumstances. It is much stronger than opinion and are less affected by the pro and con positions that are fundamental in attitude.

Epistemological Beliefs can be directly linked to individual's comprehension, meta- comprehension and interpretation of information and it effect ways of processing information by individuals, their level of understanding, higher order thinking, problem solving approaches and time and effort spent on learning [2223].

While researchers believed in unidimensional theories of epistemological beliefs, Schommer believes that they are multidimensional and that each dimension of belief may develop independently of the others [22]. There are at least five dimensions: structure, certainty, source of knowledge, control and speed of knowledge acquisition. Within each of the dimension, belief can be characterized as more or less simple and naïve versus complex and sophisticated. According to her, teachers may view knowledge as acquired gradually and incrementally over time, implying that learning takes place over an extended or unlimited time frame. Alternatively, they may view knowledge as acquired all at once or quickly, and therefore within a short and limited time frame. How teachers evaluate student responses may be, in part, governed by how teachers think knowledge is acquired. For example, if learning is viewed as gradual, teachers may prefer formative evaluation, and use student responses as feedback to plan their instruction. If they view learning as acquired quickly, they may evaluate claiming that 'either they've learned it or they haven' $t$ '.

Schraw and Olafson conceptualize three world views of the teachers: realistic, contextualistic and relativistic. Differences between these three world views are seen in teachers' different attitude towards knowledge [24]. A realist believes that knowledge is gained from experts, and that learning is a passive act; this approach to teaching closely resembles traditional, transmission model of teaching and learning. A contextualist sees themselves as a participant who constructs knowledge together with students and relativists assesses students as independent and unique persons, who form their knowledge independently. Both approaches are based on constructivist educational philosophy and are significantly more open to innovative forms of teaching. Epistemological beliefs might affect the depth to which individuals learn. There is evidence that students with naive epistemic assumptions tend to endorse surface-level strategies while students with sophisticated 
epistemological beliefs tend to endorse deep-level strategies. Reflective thinking is one tool that would help teachers to think deeply, find solutions and develop positive attitudes about inclusion. Reflection is used to describe practices ranging from analysing a single aspect of a lesson to considering the ethical, social and political implications of teaching practice [25]. Reflection is a metacognitive concept and the capacity for reflection is embedded in one's values, assumptions, and expectations. The need to prepare professionals who will be reflective practitioners has gained wide acceptance, even as one of NCTE objectives for teacher training courses. Many viewed reflective practice as the hallmark of professional competence for teachers [25-29].

It is crucial for teachers to have the skills to carry out reflective thinking themselves, and eventually become a model demonstrating the process of such thinking to their students. However, this is not the case as research has shown that teachers themselves often do not know how to be reflective or demonstrate reflective thinking [28-30]. Dewey states that teachers can be taught to 'think well' [31]. Pre service and in-service teacher preparation courses can foster and impart strategies of reflective thinking for success in an inclusive classroom.

The interest in reflective thinking was created by John Dewey in 1910. Schön distinguished between reflection in action, or simultaneous with action, and reflection on action, looking back on and learning from experience or action. Reflective thinking has following characteristics: ability to self-assess, a process of problem solving, reflection on beliefs about self and self-efficacy and critical reflection of self. Reflection is generally viewed as an incremental process [25]. There are four levels of reflection i.e. pre-reflection, surface reflection, pedagogical reflection, and critical reflection. Others most commonly depict three distinct levels of reflection [32-36]. The three levels are -

(1) an initial level focused on teaching functions, actions or skills, generally considering teaching episodes as isolated events;

(2) a more advanced level considering the theory and rationale for current practice;

(3) a higher order where teachers examine the ethical, social and political consequences of their teaching, grappling with the ultimate purposes of schooling.

Reflection aims to develop conscious control of knowledge in through a process of metacognition, so that teachers are able to self-analyse and learn to operate more effectively in demanding situations. Florian and Spratt have argued the need to ensure that teacher education program prepare teachers to be reflective practitioners who are equipped with strategies that are responsive to the individual needs of diverse learners [37]. Reflective teachers are responsive to the unique educational and emotional needs of individual students; question personal aims and actions; and constantly review instructional goals, methods, and materials [38]. There is an emerging consensus that pre-service and novice teachers could be helped to reflect at higher levels with multifaceted and strategically constructed interventions [39-44].

This study looks at reimagining the classroom where changing the teacher's approach to education from that which is focused on limitations, to one that does away with them would promote inclusive education. If an educator starts to think of the world, they are creating in the classroom instead of the impairments of the individual it changes their entire approach as an educator. "Without an understanding that our societal structures, beliefs and attitudes are what construct individuals as problematic, the notion of inclusive education would never have emerged [45-46].

Teacher preparation in inclusion is a key for implementation of inclusion. A major challenge in implementing inclusive policies is the lack of trained teachers. One of the areas of capacity building is inclusive education for children with disabilities. The focus of the study conducted is on teacher empowerment and not just teacher preparation. Make regular teachers inclusive. With the right to education and Sarva Shiksha Abhiyan more children with disabilities are going to be educated in mainstream schools. Attitude towards inclusion, Reflective thinking and epistemological beliefs are the need of the hour to facilitate inclusion. The mainstream teachers lack knowledge and information of inclusion. They are often over-burdened with curricular and co-curricular activities, which lead to very little time to spend on reflection, and understanding their own conceptions of knowing and learning. Active engagement of meaning of learning and knowledge and thinking deeply on providing meaningful learning situations to children with disabilities gets lower priority. Teachers are seen to have negative attitude towards inclusive education due to various issues. Experts are not always present to give solutions or guide the teachers. The 
present study is an attempt to highlight the importance of including modules of inclusion, reflective thinking and epistemological beliefs as integral part of teacher training programmes. This will help them recognize, understand and channelize their personal traits to manage situations arising in inclusive classes.

\section{METHODOLOGY}

The study was carried out to develop an intervention module to affect reflective thinking, epistemological beliefs and attitude towards inclusion in mainstream teachers

The objectives of the study are -

1. To study the levels of epistemological beliefs, reflective thinking and attitude towards inclusion

2. To develop an intervention module for epistemological beliefs, reflective thinking and attitude towards inclusion

3. To study the effectiveness of intervention module on reflective thinking, epistemological beliefs and attitude towards inclusion.

This was an experimental research with two group pre and post-test repeated measure design where quantitative method was applied. This method was particularly relevant to determine whether there were statistical differences among control and experimental groups' performance regarding effect of intervention module on inclusion, reflective thinking and epistemological beliefs developed in this research. The independent variable was Intervention Training Module and the dependent variables were Reflective Thinking, Epistemological Beliefs, and Attitude towards Inclusion. The main control variables were Geographical Location and Schools of Maharashtra State Secondary School Board.

The sampling was non probability purposive sampling. Out of 14 schools, 3 SSC schools were willing to be a part of the research with the schedule of intervention spread over time. A lottery method was used to assign the three schools to experimental and control group. The sample consisted of both male and female teachers. The teachers were from pre-primary to 10th standard from English medium SSC schools. Hence, the sample consisted of 94 teachers of which experimental group consisted of 40 teachers from School A. Control group had 54 teachers from two schools B and C from the region of Greater Mumbai.

Since attitude is an individual's viewpoint or disposition towards a particular 'object', and can change over a period of time, the intervention module was delivered for 46 hours over a period of three months in experimental group with repeated measures taken after three months. The control group was given pre and post-test without intervention module.

\section{Tools for the study}

Reflective thinking (RT), epistemological beliefs (EB) and Teacher's attitude towards inclusion (TA) were measured using three questionnaires: 'Do I know myself as a teacher', 'My attitude towards inclusion' and 'Epistemological Beliefs' Questionnaire. These three questionnaires have been adapted from standardized tests to reflect Indian context and cultural specificity. All three questionnaires were Likert type scale.

The questionnaire for 'reflective thinking' was adapted from Choy and Oo's Reflective Thinking Questionnaire. Teachers who are critically reflective focus their attention both inwardly at their own practice and outwardly at the social conditions in which these practices are situated. The scale assesses the four components of reflective thinking i.e., ability to self-assess, awareness of how one learns, developing lifelong learning skills and influence of belief about self and self-efficacy categorized to reflect the levels: Introductory (I), Intermediate (In) and Advanced (A). The advanced level statements (A) mean that a teacher reflects deeply on his or her practices and is constantly making efforts to improve them.

'My attitude towards inclusion' scale was adapted from Dr Barbara Larrivee's Opinions Relative to the Integration of Students with Disabilities (ORI). The items on the scale pertain to four factors-Benefits of Integration, Integrated Classroom Management, Perceived Ability to Teach Students with Disabilities, and Special Versus Integrated General Education. The higher the score, the more favourable the attitude towards inclusion.

The Epistemological Beliefs Questionnaire developed originally by Dr Marlene Schommer- Aikins was adapted for cultural and context specificity. These statements measure the factors of fixed ability, simple 
knowledge, quick learning and certain knowledge. The higher the score, the more naïve in his epistemological beliefs is the individual.

The reliability of the three tools was calculated through Cronbach alpha. Reflective Thinking was 0.84, Epistemological belief was 0.696 and inclusion was 0.73 . Thus, the final reflective thinking questionnaire had 40 items, the Epistemological beliefs questionnaire had 50 items and inclusion questionnaire had 30 items.

Intervention Module: The intervention module consisted of three sections of reflective thinking, epistemological beliefs and attitude towards inclusion. Each section was a combination of sessions with face to face interaction and self-study. The intervention module framework was content validated by experts in the field of psychology, philosophy, education and special education. The course content was validated by the experts and discussed with the teachers. The final intervention module consisted of: presentations, Videos, Student's Handbook and Trainer's Manual.

The duration of the module was for total 46 hours which consisted of $36 \mathrm{hrs}$ of face to face interactions (6 days) and $10 \mathrm{hrs}$ of activity like movies, observations and pen and pencil tasks that were self-study and assignments. The face to face sessions were conducted using interactive and participatory methodology like discussion and activities, presentations, lectures, poster making, case study. Experts from the field interacted and taught specific content.

In the intervention module, the objective of the reflective thinking section was to introduce teachers to the approach and methods of reflective practice, by raising their awareness about their own cognitive resources and how they use them in their practice so that reflective thinking develops. Through the practical exercises, participant teachers had the opportunity to reflect on their thinking capacities in the context of their practice. The aim of the section on epistemological beliefs was that the teachers should understand their personal beliefs about knowledge, which plays an important role in the teaching- learning process. It is these beliefs that partly relate to the educational decision teachers make for their students. In understanding this, the teachers would also be able to develop their own epistemological beliefs from naïve beliefs to sophisticated beliefs through activity-based sessions. Teachers were encouraged to reflect on their own epistemological beliefs and those of other teachers to investigate changes in their beliefs over the course of the intervention through activities and thought experiments.

The section on Attitude of teachers towards inclusion guided the teachers towards practicing inclusion in their own classrooms. It explained individual differences and modifications needed which could be made as per the need of the child, especially those with disabilities. The intervention module comprised of content areas like Introduction to inclusion, focus on disability and education of children with Disability and Essential support for inclusion.

\section{Procedure of development of tools and data collection}

On identifying the questionnaires covering the areas identified through literature review, discussions and focus group discussions, permission was sought from the authors and granted for their use and adaptation for the present study. After content validation of the adapted scales, they were pilot tested on 107 teachers from mainstream schools from twelve schools in Greater Mumbai district. The teachers were from primary and secondary classes. Cronbach alpha was calculated and reliability established.

Once the reliability and validity of the three tools was established and intervention module prepared, the data was collected from experimental and control group. Intervention module was administered to only the experimental group. Pre and post tests were administered for dependent variables in experimental and control groups in the same time period. Post-test 2 was administered after 3 months from the last training day. The administration of module was divided into six days of face to face interaction and other days of assignments and self-study activities.

The following is the outline of the schedule of sessions taken in the six training days over three months. The first day covered the concept of inclusion and introduction to reflective thinking. Pre-test on inclusion and reflective thinking was administered. The second day training was a revision of inclusion and introduction to various disabilities. Activities on reflective thinking and its development and introduction to 
epistemological beliefs was also covered. Pre-test of epistemological beliefs was given. The teachers were given a student's handbook that had activities on RT, EB and inclusion and was to be completed. These activities covered the hours for self-study. For the third training day, introduction to various disabilities was covered. Discussion of part handbook activities was also done along with activities for development of RT and EB. On the fourth day, revision of reflective thinking, discussion of handbook activities, activities and development of epistemological beliefs and support for inclusion was covered. Post-test for reflective thinking was taken. The fifth and sixth days covered support for inclusion, development of epistemological beliefs and brief review of inclusion, epistemological and reflective thinking Post-test for epistemological beliefs and inclusion was taken. If a test is repeated somewhere between 3 to 6 weeks respondents should not have learned much (maturation) nor remembered how they answered the first time. All tests had a gap of at least 3 weeks between pre and post-tests.

For experimental group, the post-test 2 was done after three months to see if the knowledge has sustained over the time period. For control group, only pre and post-test was done with no repeated measures. The time period corresponded with the testing in experimental group. The investigator offered to conduct the module for control group but the principals were not keen in the middle of the session so the investigator gave intervention module which included self-learning materials, teacher's manual, reference material to the principal's to be handed over to the teachers of the control group.

\section{RESULTS}

The data was analysed using $t$ test paired sample analysis, means, frequency, and ANOVA. Paired sample $t$ test was used as the means of same unit was compared at two different times.

Table 1: Pre-test and post-test mean scores, median and mode on Epistemological Beliefs (EB), Attitude towards inclusion (TA), Reflective Thinking (RT) of experimental and control group

\begin{tabular}{|c|c|c|c|c|c|c|c|c|c|c|}
\hline & & \multicolumn{3}{|c|}{ Inclusion (TA) } & \multicolumn{3}{|c|}{ Reflective thinking (RT) } & \multicolumn{3}{|c|}{ Epistemological Beliefs (EB) } \\
\hline & & Pre test & $\begin{array}{l}\text { Post } \\
\text { Test } 1\end{array}$ & $\begin{array}{l}\text { Post } \\
\text { Test } 2\end{array}$ & Pre test & $\begin{array}{l}\text { Post } \\
\text { Test } 1\end{array}$ & $\begin{array}{l}\text { Post } \\
\text { Test } 2\end{array}$ & $\begin{array}{l}\text { Pre } \\
\text { test }\end{array}$ & Post Test 1 & Post Test 2 \\
\hline \multirow{3}{*}{$\begin{array}{l}\text { Experi } \\
\text { mental } \\
\text { Group }\end{array}$} & Mean & 90 & 104 & 114 & 151 & 159 & 166 & 166 & 156 & 144 \\
\hline & Median & 91.5 & 103 & 115 & 155 & 160 & 168 & 167 & 156 & 149 \\
\hline & Mode & 100 & 98 & 116 & 158 & 167 & 168 & 161 & 163 & 160 \\
\hline \multirow{3}{*}{$\begin{array}{l}\text { Control } \\
\text { Group }\end{array}$} & Mean & 90 & 89 & & 164 & 163 & & 166 & 167 & \\
\hline & Median & 90 & 87.5 & & 164 & 166.5 & & 165 & 165.5 & \\
\hline & Mode & 94 & 96 & & 173 & 169 & & 186 & 161 & \\
\hline
\end{tabular}

The ranges of scores for inclusion vary from 0 to 180 . The average score is 90 in pre-test and it increases to 104 and 114 in post-test 1 and then post-test 2 . It indicates that level of attitudes towards inclusion increased over the months after the intervention module was administered. The median too increased from 91.5 to 115 in post-test 2 . The mode was 100 in pre-test which increased to 116 in post-test 2 . The range of scores for reflective thinking is from 40 to 200. The median is 155 in pre-test which increases 13 points to 168 in post-test 2 . The mode too has increased from 158 to 168 . The mean 151 in pre-test to 159 in post-test 1 and 166 in post-test 2.

For epistemological beliefs, the range of scores is from 50 to 250 . The median for pre-test is 167 decreased to 149 in post test2. The mode also decreases from 161 to 160 in post-test 2 . The mean is 166 in pre-test decreasing to 144 in pre-test 2 .

In control group such high difference in scores is not observed between pre-test and post test scores.

In all the three variables the scores show an increase in the level. Using t test of significance, the results show that for experimental group, the pre and post test scores after delivering the intervention module for all three variables are significant at 0.05 significance level. The obtained ' $t$ ' value for all three variables (Inclusion: 8.01, EB: -5.36, RT: 4.91) are greater than the ' $t$ ' value for two tail test (2.02). Hence the three null 
hypotheses with respect to inclusion, epistemological beliefs and reflective thinking are rejected. It means that there was a significant enhancement in reflective thinking, epistemological beliefs and attitude towards inclusion of children with disabilities after the training.

There is a significant difference in the performance of experimental group at the post-test 1 and post-test 2 . The obtained ' $t$ ' value for attitude towards inclusion, epistemological beliefs and reflective thinking (Inclusion: 7.42, EB: 7.71, RT: 8.16) are greater than the ' $t$ ' value for two tailed tests (2.02). Hence the above stated three null hypotheses with respect to inclusion, EB and RT are rejected. It is, therefore, concluded that the intervention was sustained and effective for experimental group as they performed better in the posttest 2 . The intervention had an effect on the three variables after a period of three months.

The intervention module developed was effective in bringing about this change.

In control group there was no significant difference between the scores of pre and post-test. As seen by average scores, there was no change in the three variables of teachers as compared to significant differences seen in the experimental group. For control group, all null hypotheses were accepted. It signifies that since there was no interventions given for control group teachers, their RT, EB and attitude towards inclusion did not change from pre-test to post test.

In experimental group though a trend is seen that those teachers who scored higher in attitude towards inclusion also showed more difference in their pre and post test scores in reflective thinking and epistemological beliefs. However, correlation between all three variables is non-significant.

\section{DISCUSSION}

It has been only last twenty years that we have seen a gradual shift towards inclusion with the implementing of policy of SSA, and supporting acts like RPWD and RTE. The teachers have seen segregation and special schools as the accepted way of education for children with disabilities hence their own thinking, beliefs, attitude and practice also reflects segregation to an extent. Teachers' preparation for inclusion is main focus here.

Studies support the notion that less sophisticated or more naïve teacher beliefs may be changed through interventions [24, 47-48]. In this study the results have shown that teachers have lower to medium level EB and RT scores in pre-test or hold moderately simple beliefs and underdeveloped reflective thinking. This makes them ready and amenable to change their levels when the intervention module is introduced.

For the main objectives of development and effectiveness of intervention module on attitude towards inclusion, epistemological beliefs and reflective thinking, there was no significant change in scores of pre and post-test in control group, while in experimental group there was significant difference for pre and posttests. This indicates that level of the dependent variables changed favourably after intervention module was administered. Attitudes towards inclusion are considered to have three components: cognitive, affective and behavioural. Teachers' beliefs or knowledge about educating children with special needs in inclusive settings can represent cognitive component. Feelings about educating pupils with special needs such as 'I'm afraid pupils with behaviour problems disturb the discipline in class' refer to the affective component.

The behavioural component reflects someone's predisposition to act towards the attitude object in a particular way. Changing attitudes is the first step to adopting inclusion and making it successful and it requires change in all three components. The aim of the chosen content and methodology of intervention module was to changing levels of EB, RT and attitude towards inclusion.

The inclusion module included understanding of disabilities and various methods to support inclusion in the classrooms. The teachers were allowed to explore their attitudes, beliefs and thinking through participatory and self-analysis strategies like case study, puzzles, paradoxes, poster making to allow the teachers to solve situations they encounter in their daily teaching practice and routine. Sharing positive case studies, successful strategies and actual examples from the teachers' own classes and methodology of showing videos of successful inclusion, accommodations and adaptations may have helped with getting involved with actively constructing their own schema, feeling positive, slightly confident with the concept of inclusion. Cognitive constructivism was evident as the individuals played an active role in knowledge acquisition through assimilation and accommodation of knowledge in the existing schemata [49-50]. The behaviour component could also have changed significantly as during sharing in the classroom, many teachers 
expressed that they could use these strategies in their classroom and try to include or seek help from other teachers. Thus, in post-test 1 there was a significant change in scores and change in beliefs and a deeper thinking process was initiated. Epistemological beliefs reveal positive attitudes towards education [51]. As scores for epistemological beliefs shifted positively in the post test, they could have contributed to positive shift in attitude towards inclusion.

Research indicated [52] that when the person thinks deeply, then his attitudes depend on the beliefs and ideas he generates towards the object. Reflective thinking helps to think deeper during problem solving [53]. Further, epistemological beliefs too underlie the manner in which people think. Reflection involves the following activities: making inferences, generalizations, analogies, discriminations, evaluations, feeling, remembering, problem solving, using beliefs, to make an interpretation, analysing, performing, discussing, and judging. The teachers did all these processes in order to build a new knowledge base through reframing. The module on reflective thinking could have initiated metacognitive activity in teachers showing positive shifts in score in pre and post-tests.

As the activities involve self-reflection, it also revealed to the teachers their own tacit or intuitive nature of knowledge [54]. Schon (1987) refers that knowledge which is intuitive or tacit is the way we do things or knowledge in action [55]. Knowledge in action unconsciously controls how we act in relationship to our environment in any situation. The teachers were presented with information that needed them to reframe situations and examine the long-standing perceptions and attitudes towards children with disabilities. In order to eliminate these doubts and clear the confusion, the teachers had to 'reflect' or think back on the situation to transform the dilemma to the one that no longer carried doubt or confusion [56].

The sessions on debriefing and discussions in the activity helped the teachers to identify and understand the concepts of the three variables It raised awareness of their personal feelings and attitudes towards specific issues about children with disabilities and inclusion. The teachers recognised elements of their own behaviour in the situation simulated by the activities and compare their own behaviour with that of others. Discussions and self-analysis helped them to observe and infer the impact their actions can have on the group. All the above processes that were initiated by the intervention module could have produced a significant difference in the scores on three variables at post-test of experimental group which was not present in the control group.

On repeated measures testing after three months, a significant difference was found between post-test 1 and post-test 2 . This could be because the cognitive part of attitude changed favourably. Studies have indicated that when people were exposed to external information in the training, then over the period of time (three months) they attached their own favourable thoughts about the information. There is also correlational evidence that prior attitudes play an important role in belief retrieval implying that at post-test 1 there was a significant change in beliefs and a deeper thinking process was initiated. This could have led to sustenance of attitude change at the post-test 2. Application of what the teachers had learnt in the intervention module, their positively directed feelings and problem-solving behaviour was probably validated by their experience in their own classrooms in the period between post-test 1 and post-test 2 . This could have led to sustenance of an attitude change at the post-test 2. Conceptual change happened along with resultant attitude change that signified the process by which a concept took on new meaning and to the resulting change in meaning [57].

Also, the post test1 scores showed 'revolutionary change in knowledge due to knowledge transmission but the post-test 2 showed an 'evolutionary change in knowledge' [58]. Qualitative feedback from the teachers too showed a feeling of wanting to implement the various inclusive strategies discussed during the delivery of module.

For the significant difference in the post test scores, it is possible that the teachers did this 'mental testing' of the content in the post-test 1 and then in the period between post-test 1 and post-test 2, overt action occurred to test the conclusions of mental testing. So, more reflection could have taken place in the period and the teachers tried out practical and alternative solutions learnt during the training along with analyzing the effectiveness of these solutions. By reflective teaching, teachers observe and evaluate themselves during the teaching process [59]. The epistemological scores also showed significant difference for post-test 1 and posttest 2 showing that there was a positive change in the epistemic beliefs of the teachers that persisted after three months. 
Knowledge revision and attitude change, message characteristics (i.e. comprehensibility and plausibility) interact with learner characteristics (i.e. prior knowledge, motivation, affect) to predict level of engagement with content [60]. Surprise, curiosity, and confusion arise when information conflicts with prior knowledge [61-62]. Curiosity and confusion predict greater engagement in critical thinking, which fosters increased conceptual change [63]. This was seen in the teachers as they expressed statements like: I didn't know this," "I thought we can't do anything for this child who was running out of the class always." The teachers had minimal prior knowledge and misconceptions about concepts of inclusion, support system for inclusion and concepts of reflective thinking and epistemological beliefs. Individuals studying the refutation text for knowledge revision experienced more surprise and changed more misconceptions to correct conceptions [63]. The teachers of the present study also were presented with the module that challenged many ideas held previously or provided new information that helped in resolving the incongruity, surprise, and confusion; which could have led to conceptual change.

Attitudes have a mediating role to play in changing epistemic beliefs and in this cyclical process, these beliefs play a role in determining attitudes. Epistemological beliefs underlie the manner in which people think about knowledge [63]. Since both attitudes and RT showed a change, the scores in EB could also have been influenced and vice versa [64]. These beliefs were more effective than technical knowledge in influencing how individuals organize tasks and problems and were better predictors of how teachers behaved in the classroom [65]. Epistemological beliefs vary from teacher to teacher. Those whose beliefs are not so firm are more susceptible to shifting their beliefs through intervention.

This research throws light on how teacher training programme needs to give equal importance to imparting knowledge, changing feelings and emotions, behavioural aspects, increasing the metacognitive and selfawareness and maturing beliefs of teachers to have long term effect of training on inclusion. It also shows that that how these three variables interact and scaffold with each other to build a strong base for sustaining a positive attitude for inclusion.

\section{CONCLUSIONS}

The conclusion is that the intervention module was effective and it is possible to enhance the attitudes towards inclusion, epistemological beliefs and reflective thinking for mainstream teachers through direct intervention module. Research indicates that implementing successful inclusive programme in schools is contingent on positive attitude of the teachers. This study implies that teachers' attitudes towards disabled students can be changed cognitively but it takes time to change the affective and behavioural aspect. This will ensure deep rooted change in attitude towards inclusion and reflective thinking changing to characteristic of 'reflexivity' for teachers.

The theories and studies point to the fact that attitudes are the manifestations of reflective thinking and epistemological beliefs but when we are designing and implementing modules of inclusion, we should first try to influence the epistemological beliefs and reflective thinking and then the attitude towards inclusion as feelings and beliefs have profound influence on how we receive and cognitively process the information.

Young researchers should try and find connections of how enhancing personal characteristics of teachers effect the inclusion of children with disabilities. Teachers should make reflective thinking a part of their personality so that they are always solution oriented rather than get disturbed by problems in the inclusive classrooms. They need to use reframing, which is understand things in another way, as a tool to understand situations. Teachers must be well equipped to address differences in the classroom. Inclusive education is about transformation of schools, school preparation, restructuring system, changing the role of teachers, and an inclusive education policy in every school.

\section{REFERENCES}

1. Gartia R, Sharma S. Teacher Preparation for Inclusive Education: A Major Concern for India in New Times. Revised Rates of NCERT Educational Journals (wef 1.1. 2009);45:93.

2. WHO W. World disability report. Malta: World Health Organisation, The World Bank. 2011.

3. Anderson CJ, Klassen RM, Georgiou GK. Inclusion in Australia: What teachers say they need and what school psychologists can offer. School Psychol Int 2007;28(2):131-47. 
4. Booth T, Ainscow M. Index for inclusion: Developing learning and participation in schools. Centre for Studies on Inclusive Education (CSIE), Rm 2S203 S Block, Frenchay Campus, Coldharbour Lane, Bristol BS16 1QU, United Kingdom, England (24.50 British pounds); 2002.

5. Das AK, Gichuru M, Singh A. Implementing inclusive education in Delhi, India: Regular school teachers' preferences for professional development delivery modes. Profess Dev Educ 2013;39(5):698-711.

6. Chiner E, Cardona MC. Inclusive education in Spain: how do skills, resources, and supports affect regular education teachers' perceptions of inclusion?. Int J Inclusive Educ 2013;17(5):526-41.

7. Weigel RH, Vernon DT, Tognacci LN. Specificity of the attitude as a determinant of attitude-behavior congruence. J Personal Soc Psychol 1974;30(6):724-30.

8. Roberts CM, Smith PR. Attitudes and behaviour of children toward peers with disabilities. Int J Disabil Dev Educ 1999;46(1):35-50.

9. Allport GW. Attitudes, readings in attitude theory and measurement. New York: John Willey \& Sons. 1967.

10. Barnes MC, Gaines T. Teachers' attitudes and perceptions of inclusion in relation to grade level and years of experience. Electr J Inclusive Educn 2015;3(3):3.

11. Tesser A, Leone C. Cognitive schemas and thought as determinants of attitude change. J Exp Soc Psychol 1977;13(4):340-56..

12. Vlachou AD. Struggles for inclusive education: An ethnographic study. Open University Press 1997;Oct 1.

13. Hay JF, Smit J, Paulsen M. Teacher preparedness for inclusive education. South Afr J Educn 2001;21(4):2138.

14. Angelides P, Stylianou T, Gibbs P. Preparing teachers for inclusive education in Cyprus. Teach Teacher Educn 2006;22(4):513-22.

15. Ahmmed M, Sharma U, Deppeler J. Variables affecting teachers' attitudes towards inclusive education in Bangladesh. J Res Spec Educ Needs 2012;12(3):132-40.

16. Sharma U, Moore D, Sonawane S. Attitudes and concerns of pre-service teachers regarding inclusion of students with disabilities into regular schools in Pune, India. Asia-Pacific J Teacher Educn 2009;37(3):319-31.

17. Avramidis E, Norwich B. Teachers' attitudes towards integration/inclusion: a review of the literature. Eur J Special Needs Educn 2002;17(2):129-47.

18. Jordan A, Schwartz E, McGhie-Richmond D. Preparing teachers for inclusive classrooms. Teach Teacher Educn 2009;25(4):535-42.

19. Rakap S, Kaczmarek L. Teachers' attitudes towards inclusion in Turkey. Eur J Special Needs Educn 2010;25(1):59-75.

20. Erdem M. The Effects of the Blended Teaching Practice Process on Prospective Teachers' Teaching SelfEfficacy and Epistemological Beliefs. Eurasian J Educ Res 2008;1:30.

21. Buehl MM, Alexander PA. Motivation and performance differences in students' domain-specific epistemological belief profiles. Amer Educ Res J 2005;42(4):697-726.

22. Schommer M. The influence of age and education on epistemological beliefs. Br J Educ Psychol 1998;68(4):551-62.

23. King PM, Kitchener KS. Reflective judgment: Theory and research on the development of epistemic assumptions through adulthood. Educ Psychol 2004;39(1):5-18..

24. Olafson L, Schraw G. Teachers' beliefs and practices within and across domains. Int j Educ Res 2006;45(12):71-84.

25. Larrivee B. Development of a tool to assess teachers' level of reflective practice. Reflect Pract 2008;9(3):34160.

26. Osterman KF, Kottkamp RB. Reflective practice for educators: Professional development to improve student learning. Corwin Press; 2004.

27. Schön DA, editor. The reflective turn: Case studies in and on educational practice. New York: Teachers College Press; 1991.

28. Choy SC, San Oo P. Reflective thinking and teaching practices: A precursor for incorporating critical thinking into the classroom?. Int J Instruction 2012;5(1).

29. Mirzaei F, Phang FA, Kashefi H. Measuring teachers reflective thinking skills. Proc Soc Behav Sci 2014;141:640-7.

30. Black S. Teaching students to think critically. Education Digest 2005;70(6):42-8.

31. Dewey J. How We Think. A Restatement of the Relation of Reflective Thinking to the Educative Process, Boston. (DC Heath and Company) 1933.

32. Day C. Reflection: A necessary but not sufficient condition for professional development. Br Educ Res J 1993;19(1):83-93.

33. Farrell P. School psychologists: Making inclusion a reality for all. School Psychol Int 2004;25(1):5-19.

34. Handal G, Lauvas P. Promoting reflective teaching: Supervision in practice. SRHE; 1987.

35. Jay JK, Johnson KL. Capturing complexity: A typology of reflective practice for teacher education. Teach Teacher Educn 2002;18(1):73-85.

36. Van Manen M. The tact of teaching: The meaning of pedagogical thoughtfulness. Routledge; 2016.

37. Florian L, Spratt J. Enacting inclusion: A framework for interrogating inclusive practice. Eur J Spec Needs Educ 2013;28(2):119-35.

38. Pollard A, Collins J. Reflective teaching. A\&C Black; 2005.

39. Rhine S, Bryant J. Enhancing pre- service teachers' reflective practice with digital video- based dialogue. Reflect Pract 2007;8(3):345-58.

40. Rudney GL, Guillaume AM. Reflective teaching for student teachers. Teacher Educ 1989;25(3):13-20. 
41. Russell T. Can reflective practice be taught?. Reflect Pract 2005;6(2):199-204.

42. Brookfield S. Uncovering assumptions: The key to reflective practice. Adult Learn 1992;3(4):13-8.

43. Cole AL, Knowles JG. Researching teaching: Exploring teacher development through reflexive inquiry. Allyn \& Bacon; 2000.

44. Jarvis P, Holford J, Griffin C. The theory \& practice of learning. Psychology Press; 2003.

45. Barton G, MacDonald A, Baguley M. Seeing the bigger picture: investigating tertiary arts educators' views on the Australian arts curriculum. In Proceedings of the Joint International Conference of the Australian Association for Research in Education and the Asia Pacific Educational Research Association (AARE 2012) 2012. Australian Association for Research in Education.

46. Oliver M, Barnes C. The new politics of disablement. Macmillan International Higher Education; 2012.

47. Brownlee J, Purdie N, Boulton-Lewis G. Changing epistemological beliefs in pre-service teacher education students. Teach Higher Educn 2001;6(2):247-68.

48. Hofer BK, Pintrich PR. Personal epistemology: The psychology of beliefs about knowledge and knowing. Routledge; 2012.

49. Cobb P. Constructivism in mathematics and science education. Educ Res 1994;23:4-9.

50. Piaget J, Inhelder B. The psychology of the child. New York, NY: Basic Book. Inc., Harper. 1969.

51. Silverman JC. Epistemological beliefs and attitudes toward inclusion in pre-service teachers. Teacher Educ Spec Educ 2007;30(1):42-51.

52. Briñol P, McCaslin MJ, Petty RE. Self-generated persuasion: effects of the target and direction of arguments. J Personal Soc Psychol 2012;102(5):925-30.

53. Rudd R, Baker M, Hoover T. Undergraduate agriculture student learning styles and critical thinking abilities: Is there a relationship?. J Agricult Educn 2000;41(3):2-12.

54. Taggart GL, Wilson AP. Promoting reflective thinking in teachers: 50 action strategies. Corwin Press; 2005.

55. Schon DA. Educating the reflective practitioner: toward a new design for teaching and learning in the professions. Australian J Adult Learn 2010;50(2):448-51.

56. Clarke A. Student- teacher reflection: developing and defining a practice that is uniquely one's own. Int J sci Educn 1994;16(5):497-509.

57. Chi MT, De Leeuw N, Chiu MH, LaVancher C. Eliciting self-explanations improves understanding. Cogn Sci 1994;18(3):439-77.

58. Siegler RS, Stern E. Conscious and unconscious strategy discoveries: A microgenetic analysis. J Exper Psychol Gen 1998;127(4):377-91.

59. Ghazalbash N, Afghari A. Relationship between burnout and reflective teaching among EFL teachers. Int J Foreign Lang Teach Res 2015;3(12):41-51.

60. Dole JA, Sinatra GM. Reconceptalizing change in the cognitive construction of knowledge. Educ Psychol 1998;33(2-3):109-28.

61. Brun G, Doguoglu U. Epistemology and emotions. Routledge; 2016.

62. D'Mello S, Graesser A. Dynamics of affective states during complex learning. Learn Instruct 2012;22(2):14557.

63. Muis KR, Sinatra GM, Pekrun R, Winne PH, Trevors G, Losenno KM, Munzar B. Main and moderator effects of refutation on task value, epistemic emotions, and learning strategies during conceptual change is. Contemp Educ Psychol 2018;55:155-65.

64. Güven G, Sülün Y, Çam A. The examination of elementary preservice teachers' reflective diaries and epistemological beliefs in science laboratory. Teach Higher Educn 2014;19(8):895-907.

65. Pajares MF. Teachers' beliefs and educational research: Cleaning up a messy construct. Rev Educ Res 1992;62(3):307-32.

$* * * * * * * * * * * * * * * * * * * * * * * * * * * * * * * * * * * *$

$$
\begin{gathered}
\text { Acknowledgements - Nil } \\
\text { Conflict of Interest - Nil } \\
\text { Funding - Nil }
\end{gathered}
$$

